\title{
KML001, a Telomere-Targeting Drug, Sensitizes Glioblastoma Cells to Temozolomide Chemotherapy and Radiotherapy through DNA Damage and Apoptosis
}

\author{
Seon Rang Woo, ${ }^{1,2}$ Yunhee Ham, ${ }^{1,2,3}$ Wonyoung Kang, ${ }^{1,3}$ Heekyoung Yang, ${ }^{1,3}$ Sujong Kim, ${ }^{4,5}$ \\ Juyoun Jin, ${ }^{1,3}$ Kyeung Min Joo, ${ }^{2,3,6,7}$ and Do-Hyun Nam ${ }^{1,2,3}$ \\ ${ }^{1}$ Department of Neurosurgery, Samsung Medical Center and Sungkyunkwan University School of Medicine, \\ Seoul 135-710, Republic of Korea \\ ${ }^{2}$ Cancer Stem Cell Research Center, Samsung Medical Center and Sungkyunkwan University School of Medicine, \\ Seoul 135-710, Republic of Korea \\ ${ }^{3}$ Samsung Advanced Institute for Health Sciences and Technology (SAIHST), Samsung Medical Center and Sungkyunkwan University \\ School of Medicine, Seoul 135-710, Republic of Korea \\ ${ }^{4}$ Pharmaceutical Division, Komipharm International Co., Ltd., Seoul 429-450, Republic of Korea \\ ${ }^{5}$ Graduate School of Biomedical Science \& Engineering, Hanyang University, Seoul 133-791, Republic of Korea \\ ${ }^{6}$ Department of Anatomy and Cell Biology, Samsung Medical Center and Sungkyunkwan University School of Medicine, \\ Seoul 135-710, Republic of Korea \\ ${ }^{7}$ Center for Molecular Medicine, Samsung Biomedical Research Institute, Seoul 135-710, Republic of Korea
}

Correspondence should be addressed to Kyeung Min Joo; kmjoo@skku.edu and Do-Hyun Nam; nsnam@skku.edu

Received 26 June 2014; Revised 13 August 2014; Accepted 18 August 2014; Published 10 September 2014

Academic Editor: Mariaelena Pierobon

Copyright (C) 2014 Seon Rang Woo et al. This is an open access article distributed under the Creative Commons Attribution License, which permits unrestricted use, distribution, and reproduction in any medium, provided the original work is properly cited.

Standard treatment for glioblastoma comprises surgical resection, chemotherapy with temozolomide, and radiotherapy. Nevertheless, majority of glioblastoma patients have recurrence from resistance to the cytotoxic conventional therapies. We examined combinational effects of KML001, an arsenic compound targeting telomeres of chromosomes with temozolomide or irradiation, in glioblastoma cell lines and xenograft models, to overcome the therapeutic limitation of chemoradiation therapy for glioblastoma. Although KML001 alone showed little effects on in vitro survival of glioblastoma cells, cell death by in vitro temozolomide treatment or irradiation was synergistically potentiated by combination with KML001. Since phosphorylated $\gamma-\mathrm{H} 2 \mathrm{AX}$, cleaved casepase-3, and cleaved PARP were dramatically increased by KML001, the synergistic effects would be mediated by increased DNA damage and subsequent tumor cell apoptosis. Combinatorial effects of KML001 were observed not only in chemo- and radiosensitive glioblastoma cell line, U87MG, but also in the resistant cell line, U251MG. In the U87MG glioblastoma xenograft models, KML001 did not have systemic toxicity but showed synergistic therapeutic effects in combination with temozolomide or irradiation to reduce tumor volumes significantly. These data indicated that KML001 could be a candidate sensitizer to potentiate therapeutic effects of conventional cytotoxic treatment for glioblastoma.

\section{Introduction}

Glioblastoma (GBM) is the most malignant form of primary brain tumors, which shows aggressive cancer cell proliferation, strong invasive capacity into adjacent normal brain tissue, and massive angiogenesis [1]. The current standard therapies for GBM patients are the concomitant fractionated radiotherapy and chemotherapy with DNA methylating agent, temozolomide (TMZ), following surgical removal. Nevertheless, median survival of GBM patients is known to be about 4 months without therapy and 15 months with standard therapies [2]. 
TMZ has the ability to alkylate/methylate DNA, which mostly occurs at the N7 or O6 position of guanine residues. The methylation leads to DNA strand breaks and triggers apoptotic tumor cell death. Radiation treatment also inducts DNA double strand breakage in cancer cells and thus blocks their ability to proliferate further $[3,4]$. However, chemotherapy and radiotherapy have been known to provoke various resistance mechanisms in which DNA repair may play a role [5-9]. The increased DNA repair protein, $\mathrm{O}^{6}$-methylguanineDNA methyltransferase (MGMT), is correlated with TMZ resistance in GBM $[10,11]$. Loss of MSH6, a DNA mismatch repair protein, is also found in the recurrence of temozolomide + ionizing radiation treated GBMs [12]. The disruption of Rad51-mediated homology-directed repair (HDR) or prevention of G2 checkpoint activation selectively sensitized GBM cells to radiation [13]. Therefore, the resistance to these TMZ and radiation therapies might be overcome through additional irreparable DNA damage.

Various combination strategies to overcome radiotherapy and/or TMZ chemotherapy resistance in GBM have been examined [14-16]. Some of arsenic compounds, especially, that have been used as effective chemotherapeutic agents in various solid tumors could be viable candidates [17-19]. Among them, sodium meta-arsenite, KML001, is a telomeretargeting agent, which has entered phase I clinical trials of advanced non-small cell lung cancer and other platinum responsive malignancies in ClinicalTrials.gov. KML001 directly targets telomeres of chromosomes and then provokes activation of the DNA damage signaling and rapid telomere erosion in prostate cancer cells [20]. In addition, this agent has shown synergistic antitumor activities at combination treatment with irinotecan in various tumor models [21-23]. Since KML001 enhances DNA damage and cell apoptosis, the resistance to TMZ chemotherapy and radiotherapy of GBM could be overcome through additional DNA damage by KML001.

Here, we reported the synergistic efficacy of a telomere targeting agent, KML001, combined with TMZ or radiation, which provided a candidate solution for unmet needs of conventional therapies for GBM.

\section{Materials and Methods}

2.1. Cell Culture and Reagents. The human GBM cell lines U251MG and U138MG (American Type Culture Collection, ATCC, Manassas) were cultured in Dulbecco's modified essential medium (DMEM) and U87MG and U373MG (American Type Culture Collection, ATCC, Manassas) were cultured in Eagle's minimal essential medium (MEM). All mediums were supplemented with $10 \%$ fetal bovine serum (FBS, Gibco, USA), penicillin (100 units/mL, Gibco), and streptomycin $(100 \mu \mathrm{g} / \mathrm{mL}, \mathrm{Gibco})$. These cells were maintained at $37^{\circ} \mathrm{C}$ in an incubator flushed continuously with $5 \%$ $\mathrm{CO}_{2}$.

KML001 (Sodium meta-arsenite) was purchased from Sigma-Aldrich (USA) and $100 \mathrm{mmol} / \mathrm{L}$ stock solutions were prepared in 1X phosphate buffered saline (PBS, Gibco). Working concentrations were freshly prepared daily by diluting the stock with PBS. Temozolomide was purchased by Sigma-Aldrich and dissolved in $10 \%$ dimethyl sulphoxide (DMSO, Sigma-Aldrich).

2.2. Colony Formation Assay. U251MG, U373MG, and U138MG (100 cells/2 mL medium) were seeded in 6-well plates and U87MG was seeded in $100 \mathrm{~mm}$ culture dishes (1,000 cells $/ 10 \mathrm{~mL}$ medium). After 24 hours, cells were treated with $\operatorname{KML001}(0.01,0.01,4,8,10$, and $100 \mu \mathrm{M})$, temozolomide (10 and $20 \mu \mathrm{M})$, or Irradiation $(1,2,3$, and $4 \mathrm{~Gy})$. After incubation for 10 days, all cells were fixed with $100 \%$ methanol and stained with $0.01 \%$ or $0.125 \%$ crystal violet (Sigma-Aldrich). Colonies containing more than 50 cells were counted as a representative of clonogenic cells. The survival fraction was calculated using the following formula: ((number of colonies formed after treatment)/(number of cells seeded $\times$ plating efficiency)), where plating efficiency is the number of colonies to the number of seeded cells [24].

2.3. Western Blotting Analysis. Cells were treated with KML001 (5 or $10 \mu \mathrm{M})$ or temozolomide $(100,200$ or $400 \mu \mathrm{M})$ or Irradiation (3, 6 or $9 \mathrm{~Gy}$ ) for 48 hours. All cells were lysed in NP40 lysis buffer (50 mM Tris, pH 7.4, $250 \mathrm{mM} \mathrm{NaCl,} 5 \mathrm{mM}$ EDTA, $50 \mathrm{mM} \mathrm{NaF}, 1 \mathrm{mM} \mathrm{Na} \mathrm{VO}_{4}, 1 \%$ Nonidet P40, 0.02\% $\mathrm{NaN}_{3}$ ) adding protease inhibitor cocktail tablets (SigmaAldrich) and phenylmethanesulfonyl fluoride (PMSF, SigmaAldrich). After quantitative analysis, the equal amounts of proteins were used for western blotting. Apoptotic pathway proteins were confirmed using rabbit monoclonal cleaved PARP antibody (1:1,000; Cell Signaling Technology, USA) and rabbit monoclonal caspase- 3 antibody (1:1,000; Cell Signaling Technology). Loading control was used mouse monoclonal $\beta$-actin antibody (1:5,000; Santa Cruz Biotechnology, USA). Antibodies were visualized with horseradish peroxidase-conjugated secondary antibodies (Santa Cruz Biotechnology) and the Amersham ECL Prime Western Blotting Detection Reagent (GE Healthcare, UK).

2.4. Immunocytochemistry. For immunocytochemistry (ICC) analysis, both U251MG and U87MG cells $\left(3 \times 10^{3}\right.$ cells/well $)$ were cultured on Nunc Lab-Tek II Chamber Slide System (Thermo Scientific, USA). The cells were washed three times with cold 1X PBS and fixed by 4\% paraformaldehyde for 10 minutes. The fixed cells were permeabilizated in $0.5 \%$ Triton X-100 for 10 minutes and blocked with $1 \%$ bovine serum albumin (BSA, Santa Cruz Biotechnology) for 1 hour at room temperature and then incubated with primary antibodies $\gamma$-H2AX (Upstate/Millipore, USA) at room temperature for 1 hour. Continuously, the cells were incubated with Alexaflour 488 dye-conjugated secondary antibodies (Invitrogen, USA) for 1 hour at room temperature. These cells were stained with $4^{\prime}$, 6-diamidino-2-phenylindole (DAPI, Invitrogen) for nuclear detection and viewed using a confocal laser scanning microscopy (Carl-Zeiss, Germany).

2.5. Xenograft Tumor Model. For efficacy test of KML001, temozolomide and Irradiation in vivo, we established the orthotopic xenograft models by intracranial injection using 


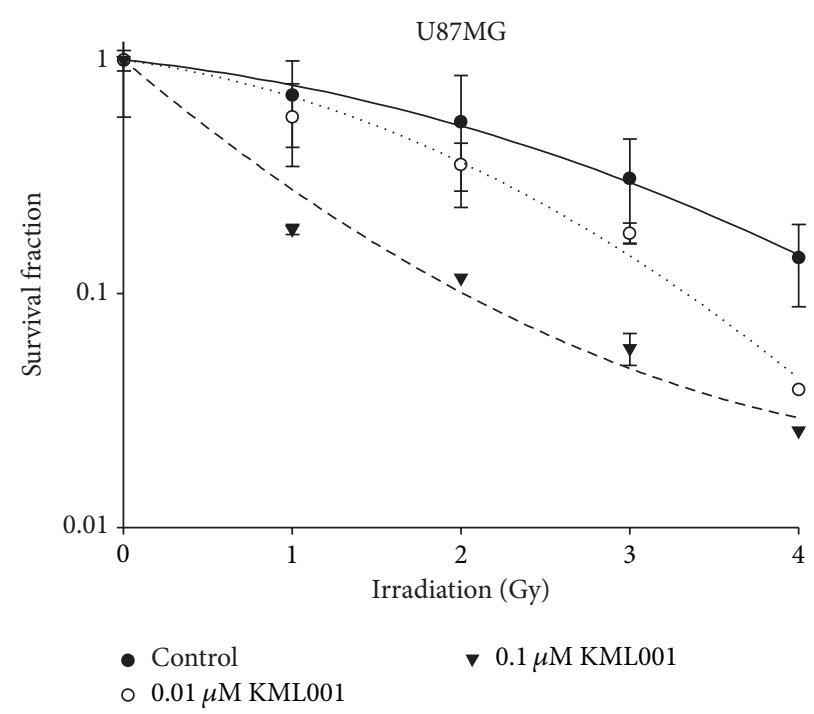

(a)

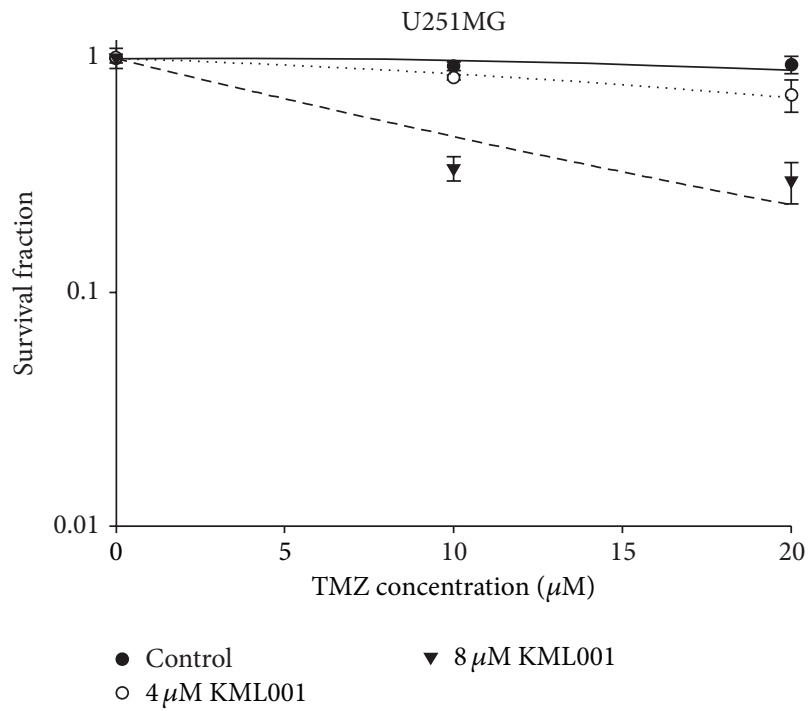

(c)

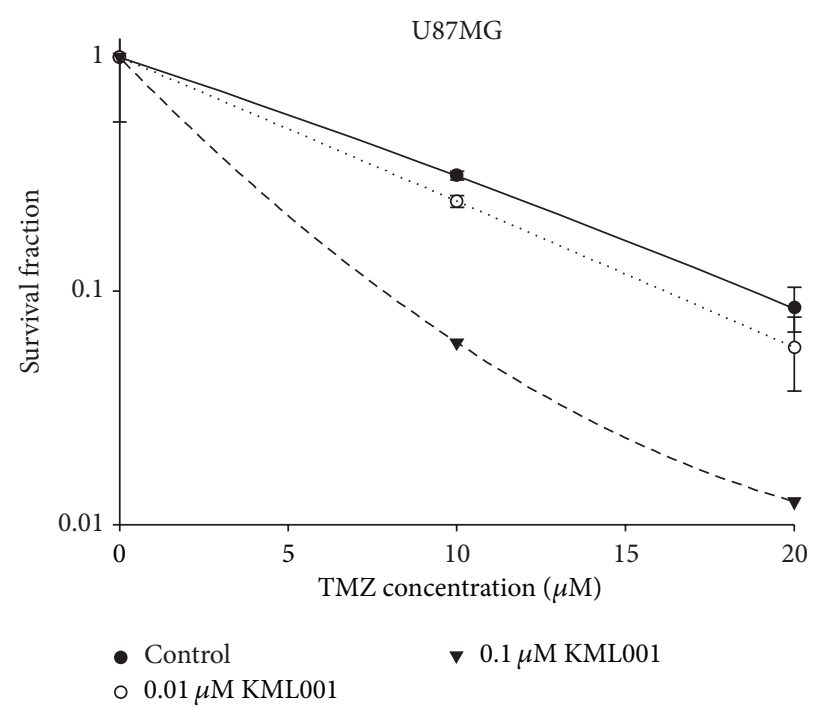

(b)

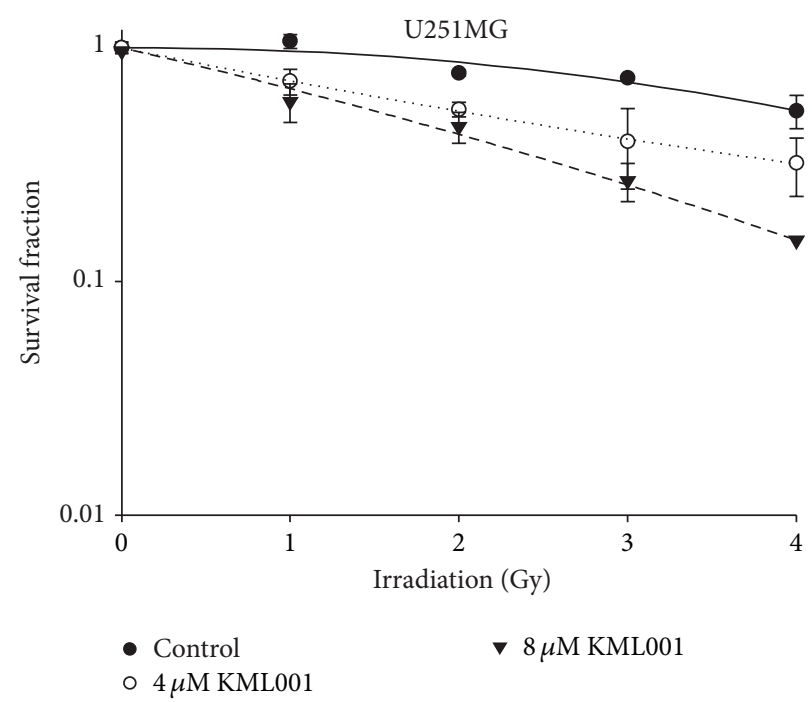

(d)

FIGURE 1: Clonogenic survival of GBM cells was significantly decreased by the combination of KML001 and TMZ or irradiation. GBM cells were seeded at 100/dish density in culture dishes and incubated for 10 days with indicated treatment. Survival fraction was demonstrated. (a) U251MG, combination with KML001 and TMZ, (b) U87MG, combination with KML001 and TMZ, (c) U251MG, combination with KML001 and irradiation, and (d) U87MG, combination with KML001 and irradiation.

6-week-old female athymic nude mice. To establish the orthotopic xenograft models, U87MG cells $\left(2 \times 10^{5} / 5 \mu \mathrm{L}\right.$ Hank's balanced salt solution (HBSS), Gibco) were stereotypically injected into the left striata of mice (coordinate; AP +0.5, ML +1.7 , DV -3.2 mm from Bregma). Each group had eight mice, and mice were medicated by KML001 $(5 \mathrm{mg} / \mathrm{kg}$ for every day via per oral) at 1 day after tumor cells injection. Temozolomide $(2 \mathrm{mg} / \mathrm{kg} \times 5$ via per oral $)$ and whole brain irradiation $(2 \mathrm{~Gy} \times 5)$ exposed at 18 days to 22 days after tumor cells injection. All animals were sacrificed at 28 days, median survival of the orthotopic xenograft model using U87MG cells. Tumor diameter was measured using vernier caliper and tumor volume determined by calculating the volume of an ellipsoid using the formula: (length $\left.\times(\text { width })^{2} \times 0.5\right)$. After mice sacrifice, the data of tumor diameter measurement were excluded in the case that cells had leaked through to cerebral ventricles.

2.6. Statistics Analysis. The results were expressed as mean values \pm standard deviation (S.D) or standard effort (S.E). Statistical comparisons were analyzed by one-way analysis of variance (ANOVA) followed by the least significant difference (LSD) test. A significant level of $P<0.05$ was used for all tests. SPSS-PASW statics software version 18.0 was used for all the statistical analyses. 


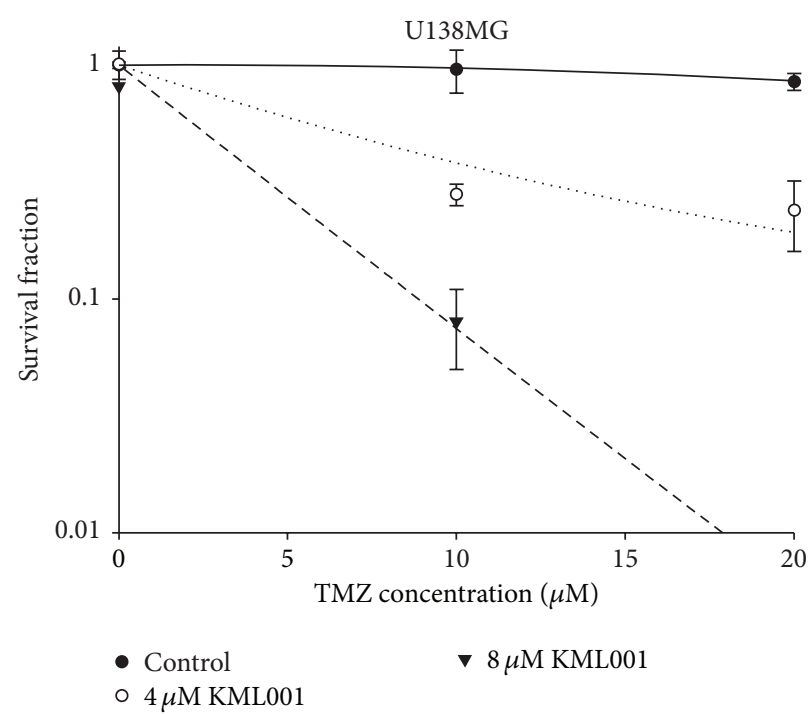

(a)

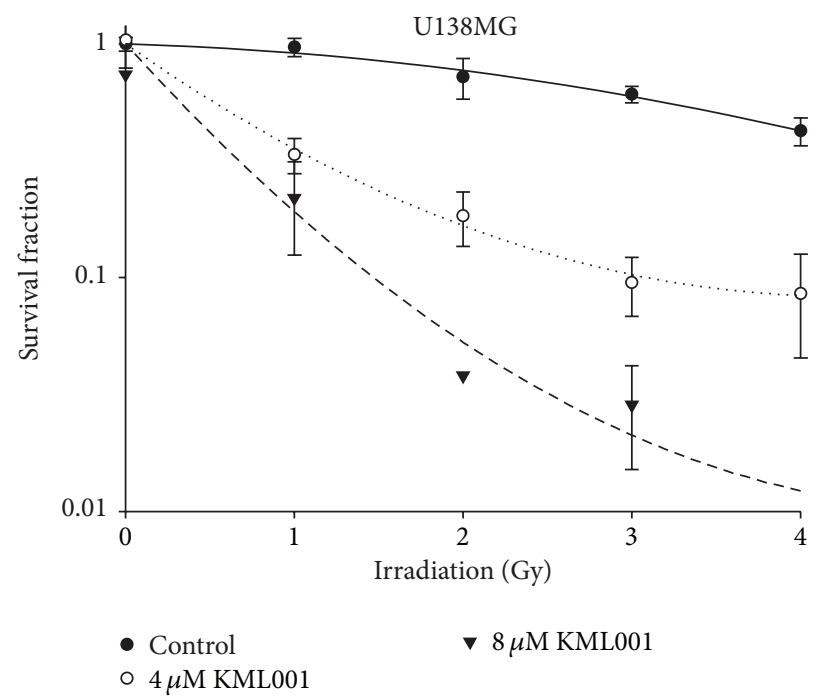

(c)

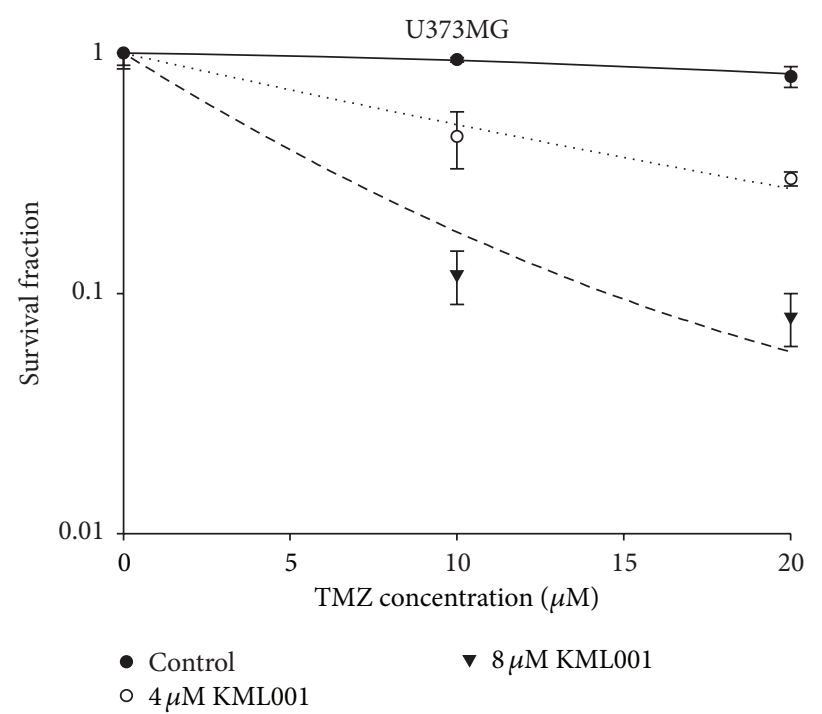

(b)

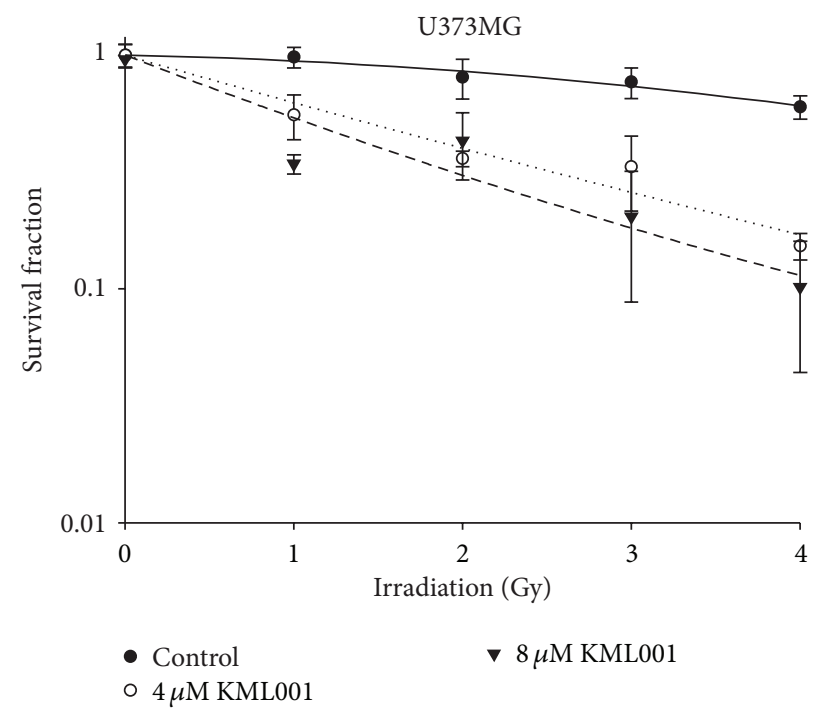

(d)

Figure 2: Clonogenic survival of GBM cells was also significantly decreased by the combination with KML001 and TMZ or irradiation in various GBM cells. GBM cells were seeded at 100/dish density in culture dishes and incubated for 10 days with indicated treatment. Survival fraction was demonstrated. (a) U373MG, combination with KML001 and TMZ, (b) U138MG, combination with KML001 and TMZ, (c) U373MG, combination with KML001 and irradiation, and (d) U138MG, combination with KML001 and irradiation.

\section{Results and Discussion}

3.1. Survival of GBM Cells Was Significantly Inhibited by Combination Treatments with KML001 and TMZ or Irradiation. We performed cell colony formation assay to determine whether the combination treatments with KML001 and TMZ or irradiation decreased GBM cell survival and increased drug sensitivity. This assay is an in vitro clonogenicity test based on the ability of a single cell to grow into a colony; it permits evaluation of the oncogenic potential of a single cell [25]. In the colony formation assay, numbers of colonies rather than total cell numbers were compared. Therefore, proliferation rate would make little effects on the results of the assay, although GBM cell lines showed different proliferation rates (Supplementary Figure 1 in Supplementary Material available online at http://dx.doi.org/10.1155/2014/747415). Moreover, differential cell proliferation prior to the treatments would not affect the results since GBM cells hardly proliferated within 24 hours after seeding (Supplementary Figure 1).

As a result, we identified that KML001 significantly increased sensitivities of both U251MG and U87MG GBM cells to TMZ and irradiation in a dose dependent manner (Figure 1). In U251MG GBM cells, $8 \mu \mathrm{M}$ KML001 decreased cell survival 3.8-fold at $20 \mu \mathrm{M}$ TMZ and 3.6-fold at $4 \mathrm{~Gy}$ irradiation (Figures 1(a) and 1(c)). In U87MG GBM cells, 


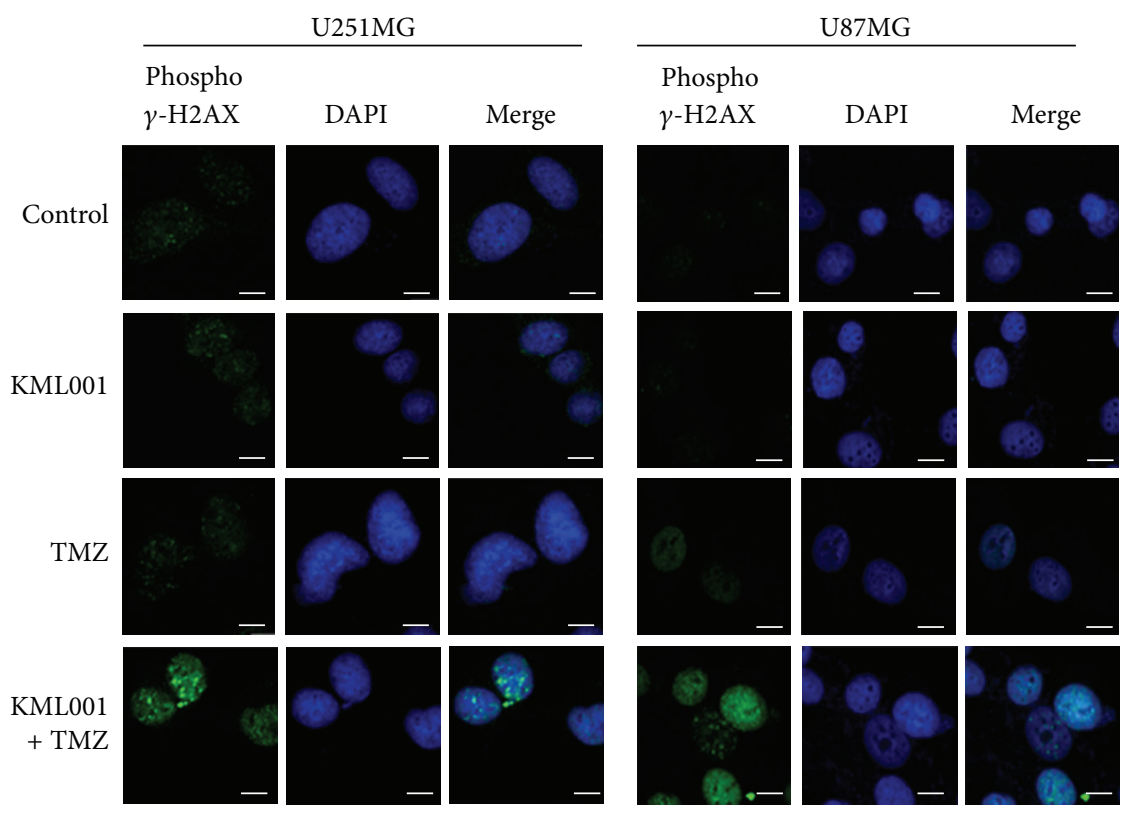

(a)

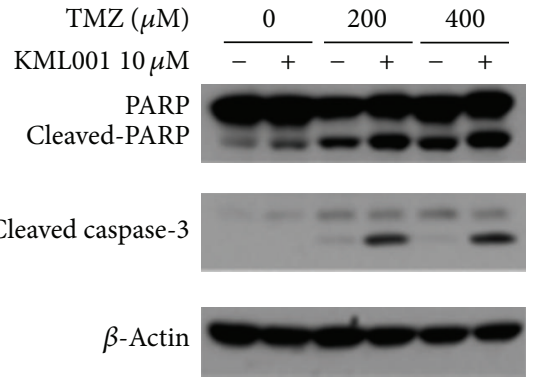

(b)

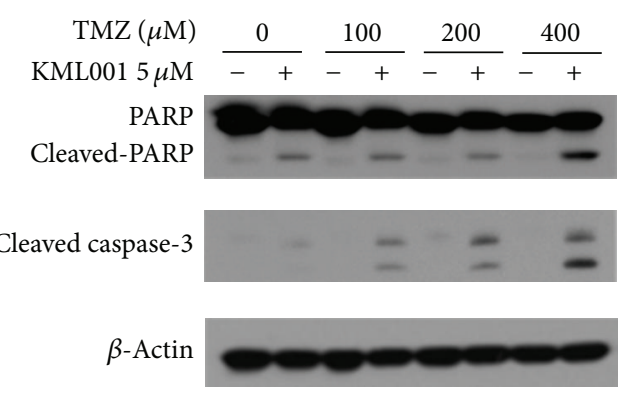

(c)

FIGURE 3: DNA damage and apoptosis were enhanced by in vitro combination treatment of KML001 and TMZ. (a) Phosphorylated $\gamma$-H2AX was detected by immunocytochemistry after 40 minutes treatment with $200 \mu \mathrm{M}$ TMZ and KML001 [10 $\mu \mathrm{M}$ (for U251MG) or $5 \mu \mathrm{M}$ (for U87MG)]. DAPI (blue) = nuclei. (b, c) U251MG (b) and U87MG (c) cells were treated in vitro as indicated for 48 hours. Western blot analysis for PARP, cleaved PARP, or cleaved caspase- 3 was performed. $\beta$-actin $=$ loading control.

$0.1 \mu \mathrm{M}$ KML001 decreased cell survival 6.7-fold at $20 \mu \mathrm{M}$ TMZ and 5.0-fold at 4 Gy irradiation (Figures $1(\mathrm{~b})$ and $1(\mathrm{~d})$ ). Other GBM cell lines such as U373MG (Figures 2(a) and 2(c)) and U138MG (Figures 2(b) and 2(d)) also showed similar synergistic effects of KML001.

GBM is one of the most resistant tumors to conventional cytotoxic therapies, which results in minimal survival benefit from standard chemotherapy and radiotherapy. To overcome resistance, current studies concentrate on combinations with other agents and on development of novel moleculartargeting agents [14-16]. Previously, the anticancer efficacy of KML001 in combination with irinotecan was evaluated by Moon et al. [21]. They showed that vascular disrupting properties and DNA damage effects at the telomeres of chromosome of KML001 were involved in the enhanced anticancer activity of irinotecan [21]. We also observed that KML001 significantly enhanced in vitro sensitivity of TMZ and irradiation in 4 independent GBM cell lines. These results suggested that KML001 could acts as a chemo- and radiosensitizer in GBM.

On the other hand, we also recognized that U87MG cell line showed sensitive response to both TMZ and irradiation, while the U251MG cell line was resistant. Therefore, we further evaluated the differential changes in DNA damage and apoptosis signaling in vitro and tumor growth of chemoand radioresistant U251MG cells, compared with those of chemo- and radiosensitive U87MG cells, in vivo.

3.2. DNA Damage and Cell Apoptosis Induced by TMZ or Irradiation Were Enhanced by KML001. TMZ and irradiation lead to cancer cell apoptosis through DNA mismatch-repair $[10,11]$ and DNA double strand break (DSB) events [3]. Previously, many studies focused on the explanation for mechanisms of the phosphorylated $\gamma-\mathrm{H} 2 \mathrm{AX}$ in DNA damage signaling and repair [26-28]. Notably examination of $\gamma$-H2AX foci formation is a powerful tool to measure DNA DSB formation 


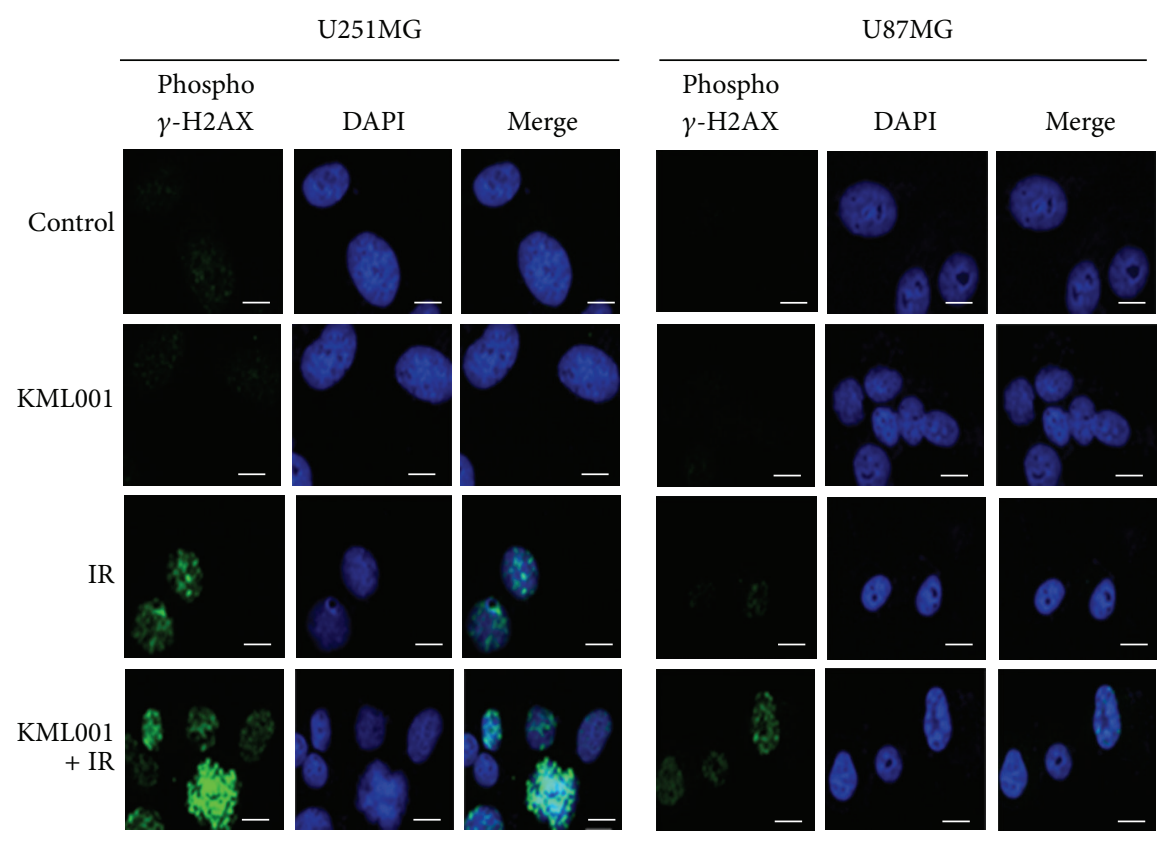

(a)

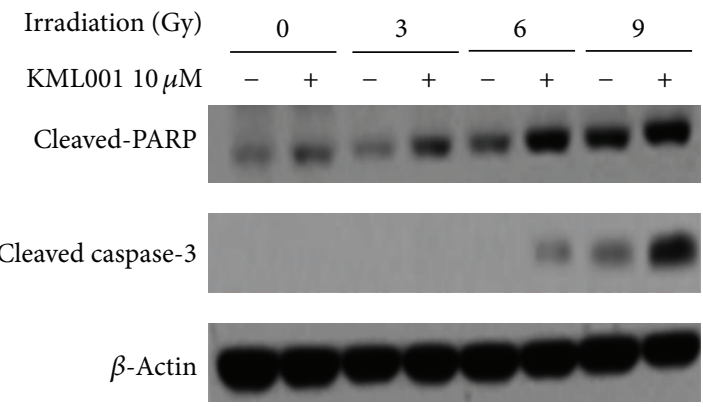

(b)

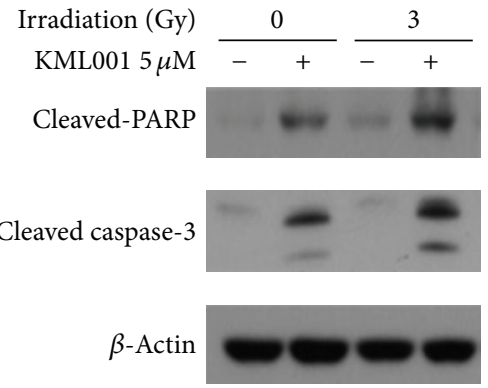

(c)

FIGURE 4: DNA damage and apoptosis were enhanced by the in vitro combination treatment of KML001 and irradiation. (a) Phosphorylated $\gamma$-H2AX was detected by immunocytochemistry after 40 minutes treatment with 3 Gy irradiation and KML001 $10 \mu \mathrm{M}$ (for U251MG) or $5 \mu \mathrm{M}$ (for U87MG). DAPI (blue) = nuclei. (b, c) U251MG (b) and U87MG (c) cells were treated in vitro as indicated for 48 hours. Western blot analysis against PARP, cleaved PARP, or cleaved caspase- 3 was performed. $\beta$-actin $=$ loading control.

and cellular response to genomic damage [28]. In addition, caspase- 3 is frequently activated by death protease to catalyze the specific cleavage of many key cellular apoptosis-inducing proteins including PARP $[29,30]$. Therefore, to elucidate the combination mechanism of KML001 in GBM cells, we analyzed phosphorylated $\gamma-\mathrm{H} 2 \mathrm{AX}$ formation and caspase3/PARP cleavage in response to the combination treatments.

Phosphorylated $\gamma$-H2AX a DNA DSB marker was detected in the KML001 and TMZ combination group in both TMZ-resistant U251MG and sensitive U87MG cell lines, while the KML001 or TMZ single treatments showed little phosphorylated $\gamma$-H2AX by immunocytochemistry (Figure 3(a)). Moreover, $10 \mu \mathrm{M}$ KML001 combination dramatically enhanced the protein expression of cleaved PARP and caspase- 3 at 200 and $400 \mu \mathrm{M}$ TMZ treatment in TMZresistant U251MG cells (Figure 3(b)). In TMZ-sensitive U87MG cells, cleaved PARP and caspase-3 were hardly observed by TMZ singe treatment. In contrast, $5 \mu \mathrm{M}$ KML001 combined with $400 \mu \mathrm{M}$ TMZ strikingly increased cleaved PARP level, while TMZ provoked a dose-dependent increase in cleaved caspase-3 upon combination with $5 \mu \mathrm{M}$ KML001 (Figure 3(c)).

Next, we performed the same experiments with the combination of KML001 with irradiation. In both radiationresistance U251 MG and sensitive U87MG, the phosphorylated $\gamma$-H2AX was dramatically increased by the combination treatment of KML001 and 3 Gy irradiation, compared with the control or single treatments (Figure 4(a)). In common with the combination treatment with KML001 and TMZ, KML001 increased the protein expression of the apoptotic marker proteins, cleaved PARP and caspase- 3 at 3 Gy irradiation in U251MG cells (Figure 4(b)). In U87MG cells, KML001 also dramatically potentiated the irradiation dose-dependent increase in cleaved PARP and caspase-3 (Figure 4(c)). 


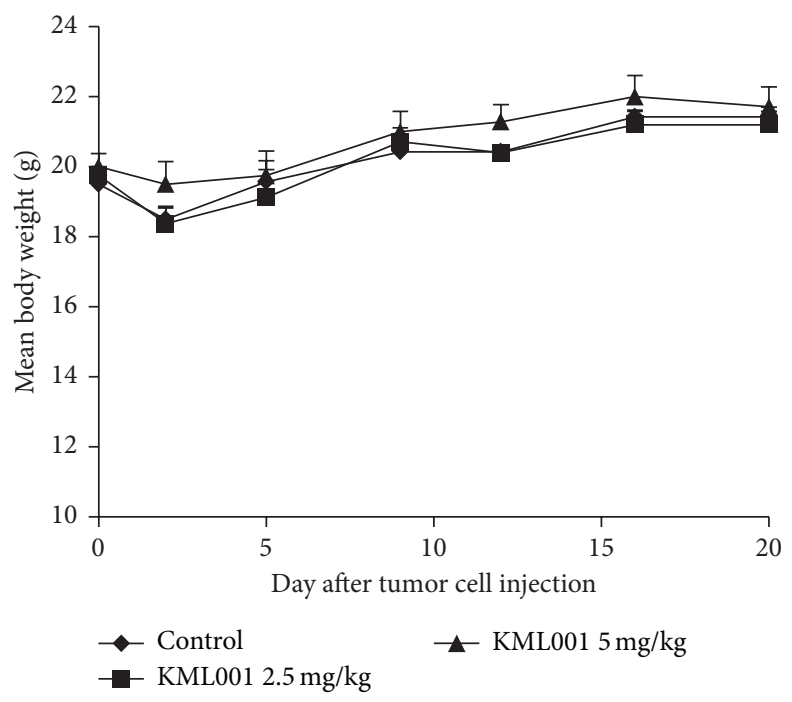

(a)
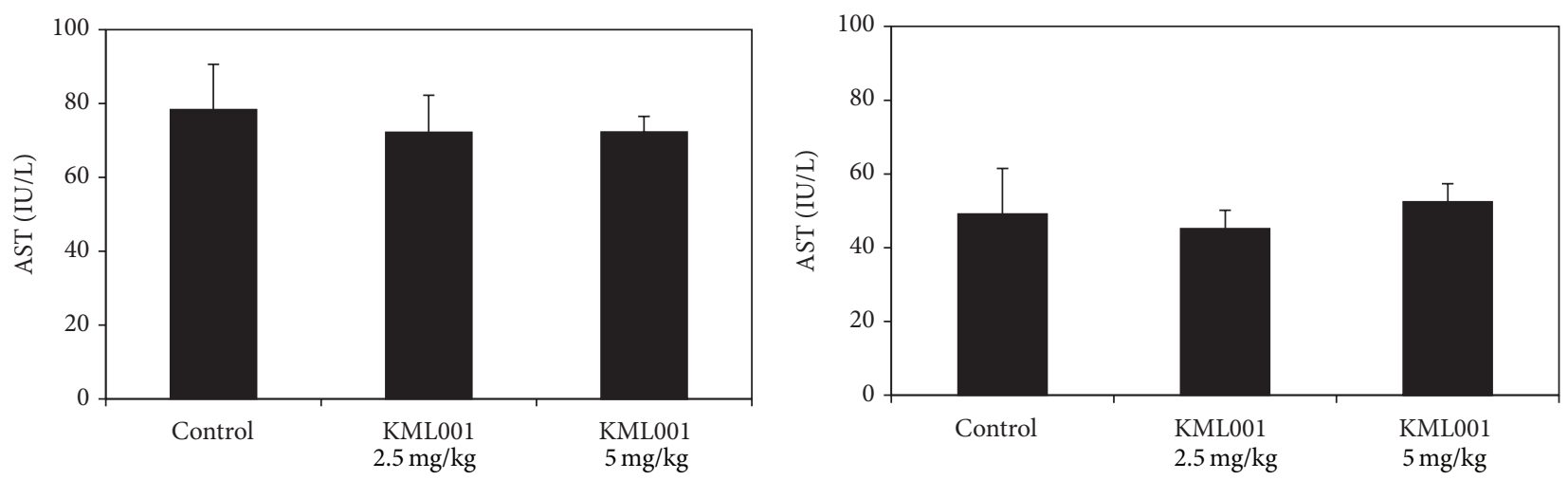

(b)

FIGURE 5: KML001 showed little in vivo systemic toxicity in the U87MG GBM orthotopic xenograft models. KML001 (2.5 or 5 mg/kg) was orally administrated into U87MG orthotopic xenograft models every day from 1 day after tumor cell implantation. (a) Body weight was measured twice a week until 20 days after tumor cell implantation. (b) The level of AST and ALT was analyzed in mice serum on the 20th day after tumor cell implantation.

Arsenic based pharmaceuticals have been reported to inhibit viability of pancreatic cancer stem cells [22]. Accordingly, the combination treatments with low dose gemcitabine synergistically inhibited tumorigenesis of pancreatic xenograft model [22]. The combination treatment with arsenic compounds and cytotoxic agents synergistically enhanced DNA damage and cell apoptosis [23]. Recently, trivalent arsenical KML001 was also reported to induce the ROS-associated DNA damage via direct biding to telomeric sequences in prostate cancer cells [20]. Binding with telomeric sequences is enhanced when cells have short telomeres, which results in cancer cell specific effects of KML001; cancer cells have shorter telomeres than somatic cells such as astrocytes [20,31]. Although the activity and/or mutation status of telomerase reverse transcriptase (TERT) could make influences on the length of telomere, KML001 has little effect on telomerase activity [20]. Moreover, KML001 provoked apoptosis of TERT-low leukemia cells [32]. Therefore, cytotoxic activities of KML001 would be directly affected by the telomere length, not by the mutation status, expression, and/or activities of TERT in cancer cells.

To conclude in this study, we identified that KML001 combined with TMZ or irradiation potentiated DNA damage and subsequent GBM cell apoptosis. Since KML001 induced therapeutic sensitivity to TMZ and irradiation in the chemoand radioresistant cell, U251MG, as well as the chemoand radiosensitive cell, U87MG, KML001 would have broad therapeutic indications for GBM.

3.3. KML001 Combined with TMZ or Irradiation Synergistically Decreased Tumor Volume in U87MG GBM Orthotopic Xenograft Models. We employed U87MG orthotopic xenograft models to confirm the in vitro combinational treatment result of KML001, in vivo. Firstly, we tested whether KML001 had in vivo toxicity by measuring body weight and liver enzyme (AST and ALT) level changes in the orthotopic model. KML001 treatment resulted in no change in body 


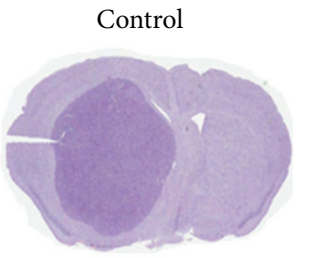

TMZ
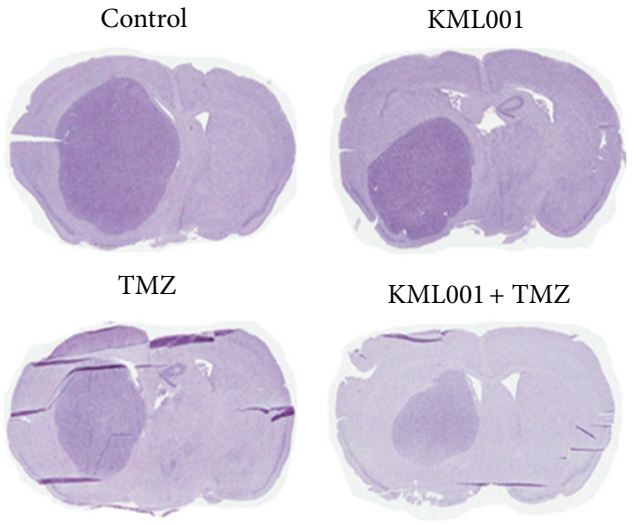

KML001+ TMZ

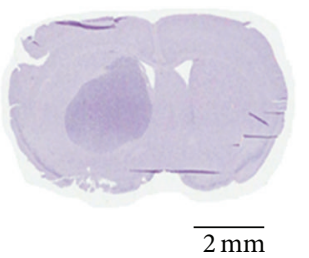

(a)
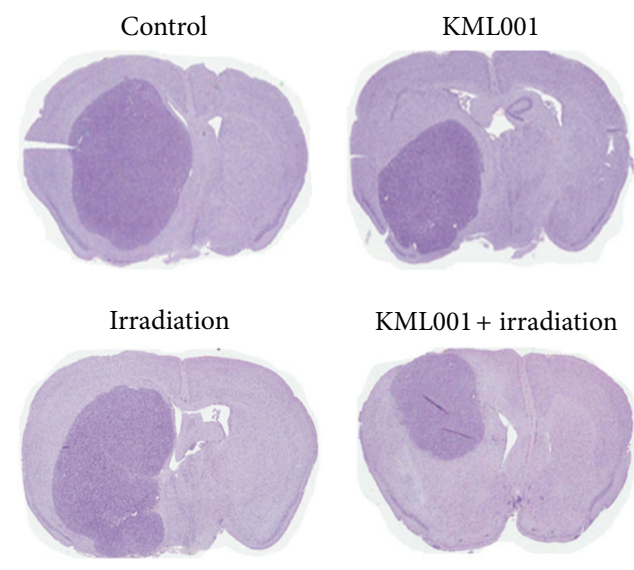

KML001 + irradiation

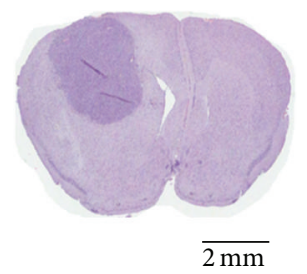

(c)

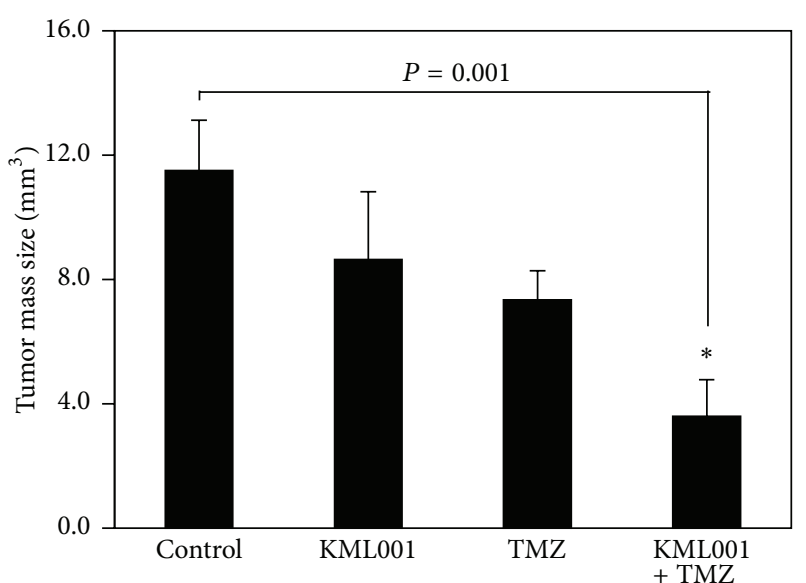

(b)

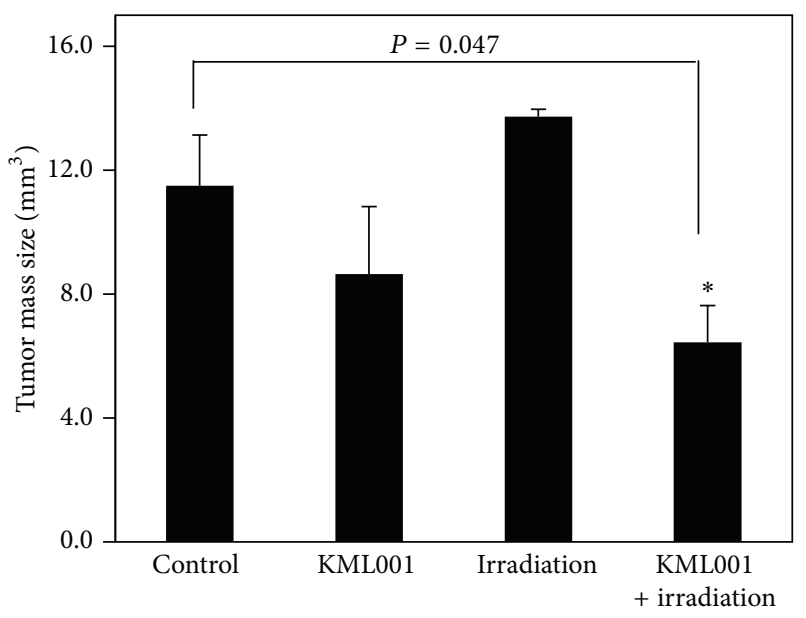

(d)

FIGURE 6: Tumor volume of U87MG xenograft tumors was significantly reduced by the combination treatment with KML001 and TMZ or irradiation. The orthotopic xenograft models were treated with normal saline (control, every day from 1 day after tumor cell implantation), KML001 ( $5 \mathrm{mg} / \mathrm{kg}$, every day from 1 day after tumor cell implantation), TMZ ( $2 \mathrm{mg} / \mathrm{kg}, 5$ times daily from 18 th to $22 \mathrm{nd}$ day after tumor cell implantation), irradiation ( 2 Gy, 5 times daily from 18th to 22nd day after tumor cell implantation), or KML001 + TMZ or irradiation. Tumor volume (length $\left.\times(\text { width })^{2} \times 0.5\right)$ was analyzed on the 28 th day after tumor cell implantation. (b and d) Data represent mean \pm standard deviation. ${ }^{*} P<0.05$.

weight nor in levels of AST and ALT, validating low in vivo toxicity (Figure 5).

The U87MG orthotopic xenograft models were treated with (1) control (normal saline, every day from 1 day after tumor cell implantation), (2) KML001 (5 mg/kg, every day from 1 day after tumor cell implantation), (3) TMZ (2 mg/kg, 5 times daily from 18 th to 22 nd day after tumor cell implantation) or irradiation ( $2 \mathrm{~Gy}, 5$ times daily from 18th to $22 \mathrm{nd}$ day after tumor cell implantation), or (4) KML001 + TMZ or irradiation. Tumor volume was analyzed on the 28th day after tumor cell implantation. The combination treatment with KML001 and TMZ significantly decreased xenograft tumor volume, while the single treatments of KML001 or TMZ slightly decreased tumors size (Figure 6(a)). The combination treatment with KML001 and TMZ decreased tumor volume 2.4- and 2.0-fold compared with KML001 and TMZ single therapy, respectively (Figure 6(b)). Similarly, the combination treatment with KML001 and irradiation reduced tumor volume significantly (Figure 6(c)). Although irradiation showed no effects (Figure 6(c) bottom and left), tumor volume decreased 1.8 -fold by the combination therapy compared with KML001 single treatment (Figure 6(d)).

According to a previous report, the treatment with TMZ caused a substantial growth delay of U87MG xenografts tumor, while irradiation did not affect tumor growth [33]. Here, we also confirmed that TMZ had higher anticancer effects than irradiation in U87MG xenografts. Furthermore, we identified that KML001 not only potentiated antitumor effects of TMZ against U87MG xenograft tumors but also reversed in vivo resistance of U87MG cells to irradiation. Although tumor volume decreased by single treatments of TMZ or KML001, they were not statically significant. Only xenograft tumors were significantly reduced by the combination treatment with KML001 and TMZ $(P=0.001)$ 
or irradiation $(P=0.047)$ compared with the nontreatment group.

\section{Conclusions}

In this study, we demonstrated that KML001 potentiated antitumor effects of conventional cytotoxic treatment for GBM: TMZ chemotherapy and radiotherapy in vitro and in vivo. These synergistic effects could be mediated by increased DNA damage, which would further provoke GBM cell apoptosis. Since KML001 alone did not show any in vivo systemic toxicities, KML001 could be a viable candidate for a combinational sensitizer in GBM treatment.

\section{Conflict of Interests}

The authors declare that there is no conflict of interests regarding the publication of this paper.

\section{Authors' Contribution}

Seon Rang Woo, Yunhee Ham, and Wonyoung Kang contributed equally to this work.

\section{Acknowledgments}

This research was supported by a Grant of the Korea Health Technology R\&D Project through the Korea Health Industry Development Institute (KHIDI), funded by the Ministry of Health \& Welfare, Republic of Korea (HI09C1552).

\section{References}

[1] A. Golebiewska, S. Bougnaud, D. Stieber et al., "Side population in human glioblastoma is non-tumorigenic and characterizes brain endothelial cells," Brain, vol. 136, no. 5, pp. 1462-1475, 2013.

[2] D. R. Johnson and B. P. O'Neill, “Glioblastoma survival in the United States before and during the temozolomide era," Journal of Neuro-Oncology, vol. 107, no. 2, pp. 359-364, 2012.

[3] S. P. Jackson and J. Bartek, "The DNA-damage response in human biology and disease," Nature, vol. 461, no. 7267, pp. 10711078, 2009.

[4] R. Miralbell, F. Mornex, R. Greiner et al., "Accelerated radiotherapy, carbogen, and nicotinamide in glioblastoma multiforme: report of European Organization for Research and Treatment of Cancer Trial 22933," Journal of Clinical Oncology, vol. 17, no. 10, pp. 3143-3149, 1999.

[5] G. Frosina, "DNA repair and resistance of gliomas to chemotherapy and radiotherapy," Molecular Cancer Research, vol. 7, no. 7, pp. 989-999, 2009.

[6] T. Helleday, E. Petermann, C. Lundin, B. Hodgson, and R. A. Sharma, "DNA repair pathways as targets for cancer therapy," Nature Reviews Cancer, vol. 8, no. 3, pp. 193-204, 2008.

[7] M. R. Kelley and M. L. Fishel, "DNA repair proteins as molecular targets for cancer therapeutics," Anti-Cancer Agents in Medicinal Chemistry, vol. 8, no. 4, pp. 417-425, 2008.

[8] J. F. Parkinson, H. T. Wheeler, and K. L. McDonald, "Contribution of DNA repair mechanisms to determining chemotherapy response in high-grade glioma," Journal of Clinical Neuroscience, vol. 15, no. 1, pp. 1-8, 2008.

[9] J. N. Sarkaria, G. J. Kitange, C. D. James et al., "Mechanisms of chemoresistance to alkylating agents in malignant glioma," Clinical Cancer Research, vol. 14, no. 10, pp. 2900-2908, 2008.

[10] H. S. Friedman, T. Kerby, and H. Calvert, "Temozolomide and treatment of malignant glioma," Clinical Cancer Research, vol. 6, no. 7, pp. 2585-2597, 2000.

[11] M. M. Mrugala, M. C. Chamberlain, and F. Hutchinson, "Mechanisms of disease: temozolomide and glioblastomalook to the future," Nature Clinical Practice Oncology, vol. 5, no. 8, pp. 476-486, 2008.

[12] D. P. Cahill, K. K. Levine, R. A. Betensky et al., "Loss of the mismatch repair protein MSH6 in human glioblastomas is associated with tumor progression during temozolomide treatment," Clinical Cancer Research, vol. 13, no. 7, pp. 20382045, 2007.

[13] S. C. Short, C. Martindale, S. Bourne, G. Brand, M. Woodcock, and P. Johnston, "DNA repair after irradiation in glioma cells and normal human astrocytes," Neuro-Oncology, vol. 9, no. 4, pp. 404-411, 2007.

[14] F. Ohka, A. Natsume, and T. Wakabayashi, "Current trends in targeted therapies for glioblastoma multiforme," Neurology Research International, vol. 2012, Article ID 878425, 13 pages, 2012.

[15] J. Kahn, T. J. Hayman, M. Jamal et al., "The mTORC1/mTORC2 inhibitor AZD2014 enhances the radiosensitivity of glioblastoma stem-like cells," Neuro-Oncology, vol. 16, no. 1, pp. 29-37, 2014.

[16] S. Kuger, D. Graus, R. Brendtke et al., "Radiosensitization of glioblastoma cell lines by the dual PI3K and mTOR inhibitor NVP-BEZ235 depends on drug-irradiation schedule," Translational Oncology, vol. 6, no. 2, pp. 169-179, 2013.

[17] C. Yedjou, P. Tchounwou, J. Jenkins, and R. McMurray, "Basic mechanisms of arsenic trioxide (ATO)-induced apoptosis in human leukemia (HL-60) cells," Journal of Hematology and Oncology, vol. 3, article 28, 2010.

[18] M. Z. Dizaji, M. Malehmir, A. Ghavamzadeh, K. Alimoghaddam, and S. H. Ghaffari, "Synergistic effects of arsenic trioxide and silibinin on apoptosis and invasion in human glioblastoma U87MG cell line," Neurochemical Research, vol. 37, no. 2, pp. 370-380, 2012.

[19] K. J. Cohen, I. C. Gibbs, P. G. Fisher, R. J. Hayashi, M. E. MacY, and L. Gore, "A phase i trial of arsenic trioxide chemoradiotherapy for infiltrating astrocytomas of childhood," Neuro-Oncology, vol. 15, no. 6, pp. 783-787, 2013.

[20] P. Phatak, F. Dai, M. Butler et al., "KML001 cytotoxic activity is associated with its binding to telomeric sequences and telomere erosion in prostate cancer cells," Clinical Cancer Research, vol. 14, no. 14, pp. 4593-4602, 2008.

[21] C. H. Moon, S. J. Lee, H. Y. Lee et al., "KML001 displays vascular disrupting properties and irinotecan combined antitumor activities in a murine tumor model," PLoS ONE, vol. 8, no. 1, Article ID e53900, 2013.

[22] J. B. Han, F. Sang, J. J. Chang et al., "Arsenic trioxide inhibits viability of pancreatic cancer stem cells in culture and in a xenograft model via binding to SHH-Gli," OncoTargets and Therapy, vol. 6, pp. 1129-1138, 2013.

[23] H. Zhong, J. Zhao, H. Qi et al., "Gemcitabine and carboplatin demonstrate synergistic cytotoxicity in cervical cancer cells by inhibiting DNA synthesis and increasing cell apoptosis," OncoTargets and Therapy, vol. 6, pp. 1707-1717, 2013. 
[24] N. A. P. Franken, H. M. Rodermond, J. Stap, J. Haveman, and C. van Bree, "Clonogenic assay of cells in vitro," Nature Protocols, vol. 1, no. 5, pp. 2315-2319, 2006.

[25] N. A. P. Franken, H. M. Rodermond, J. Stap, J. Haveman, and C. van Bree, "Clonogenic assay of cells in vitro," Nature Protocols, vol. 1, no. 5, pp. 2315-2319, 2006.

[26] M. Podhorecka, A. Skladanowski, and P. Bozko, "H2AX phosphorylation: its role in DNA damage response and cancer therapy," Journal of Nucleic Acids, vol. 2010, Article ID 920161, 9 pages, 2010.

[27] L. Geng, K. C. Cuneo, A. Fu, T. Tu, P. W. Atadja, and D. E. Hallahan, "Histone deacetylase (HDAC) inhibitor LBH589 increases duration of $\gamma$-H2AX foci and confines HDAC4 to the cytoplasm in irradiated non-small cell lung cancer," Cancer Research, vol. 66, no. 23, pp. 11298-11304, 2006.

[28] T. M. Marti, E. Hefner, L. Feeney, V. Natale, and J. E. Cleaver, "H2AX phosphorylation within the G1 phase after UV irradiation depends on nucleotide excision repair and not DNA double-strand breaks," Proceedings of the National Academy of Sciences of the United States of America, vol. 103, no. 26, pp. 98919896, 2006.

[29] A. G. Porter and R. U. Jänicke, "Emerging roles of caspase-3 in apoptosis," Cell Death and Differentiation, vol. 6, no. 2, pp. 99104, 1999.

[30] A. H. Boulares, A. G. Yakovlev, V. Ivanova et al., "Role of poly(ADP-ribose) polymerase (PARP) cleavage in apoptosis. Caspase 3-resistant PARP mutant increases rates of apoptosis in transfected cells," Journal of Biological Chemistry, vol. 274, no. 33, pp. 22932-22940, 1999.

[31] B.-G. Jeon, B. M. Kumar, E.-J. Kang et al., "Differential cytotoxic effects of sodium meta-arsenite on human cancer cells, dental papilla stem cells and somatic cells correlate with telomeric properties and gene expression," Anticancer Research, vol. 31, no. 12, pp. 4315-4328, 2011.

[32] W. Glienke, K. U. Chow, N. Bauer, and L. Bergmann, "Downregulation of wtl expression in leukemia cell lines as part of apoptotic effect in arsenic treatment using two compounds," Leukemia and Lymphoma, vol. 47, no. 8, pp. 1629-1638, 2006.

[33] A. Diaz, R. Blanco, M. Lemm et al., "Preclinical efficacy of nimotuzumab, an anti-EGFR monoclonal antibody as a single agent therapy in human GBM U87MG xenografts," Journal of Cancer Therapy, vol. 3, pp. 245-255, 2012. 


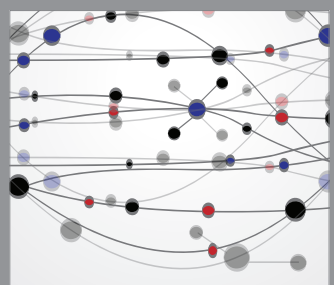

The Scientific World Journal
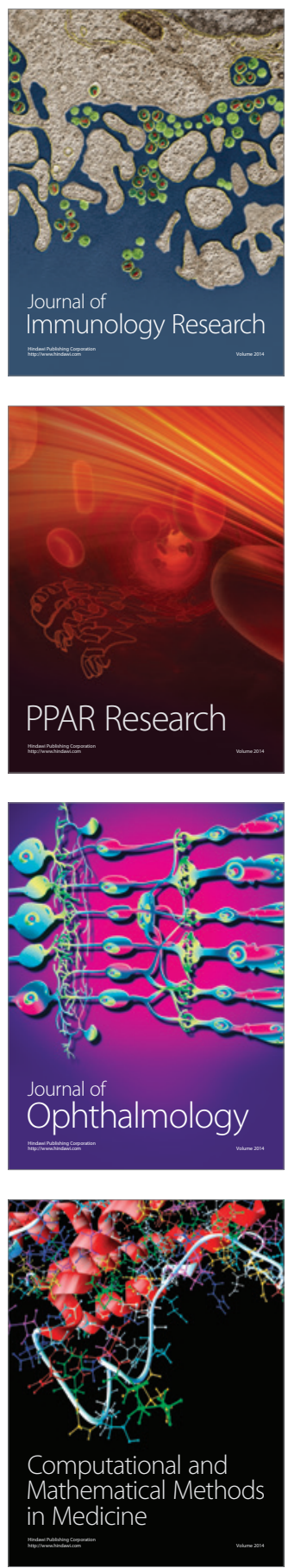

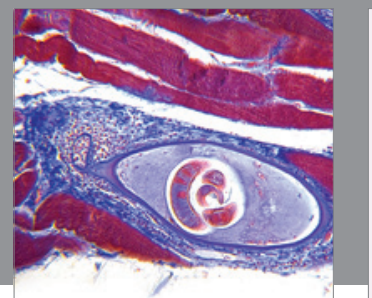

Gastroenterology

Research and Practice
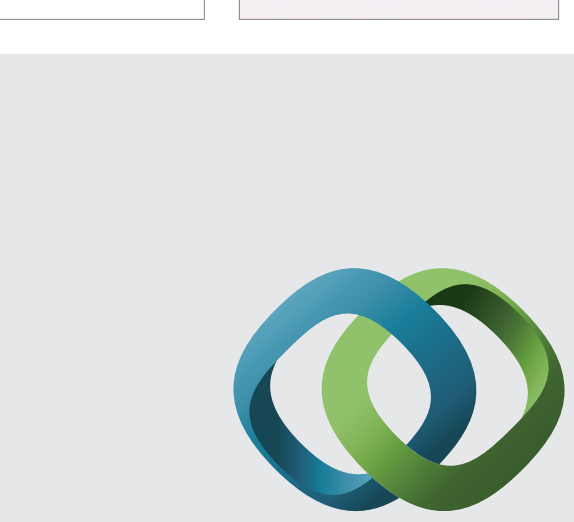

\section{Hindawi}

Submit your manuscripts at

http://www.hindawi.com
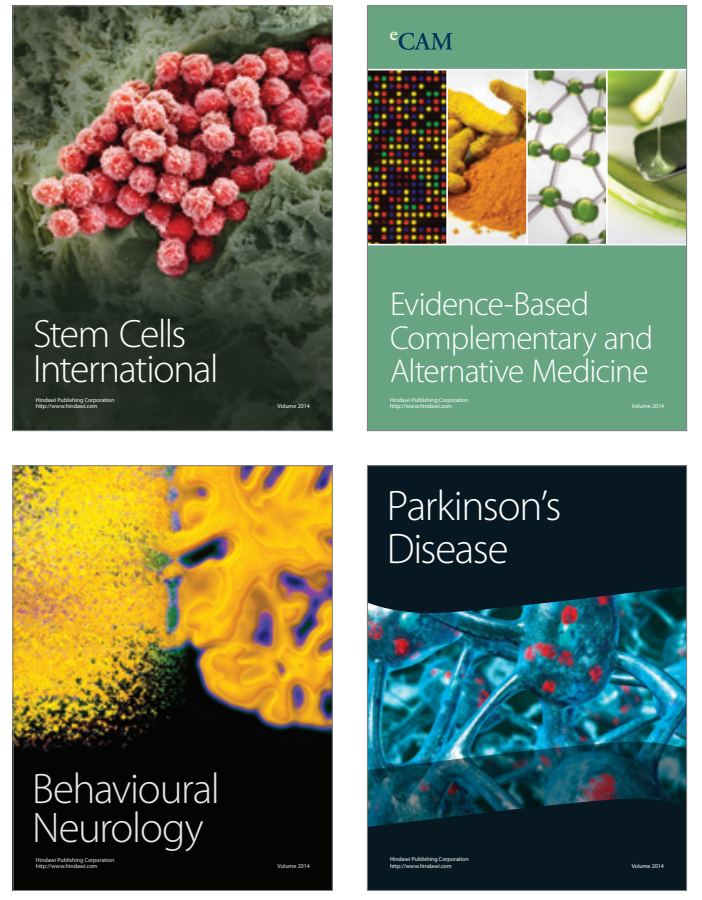
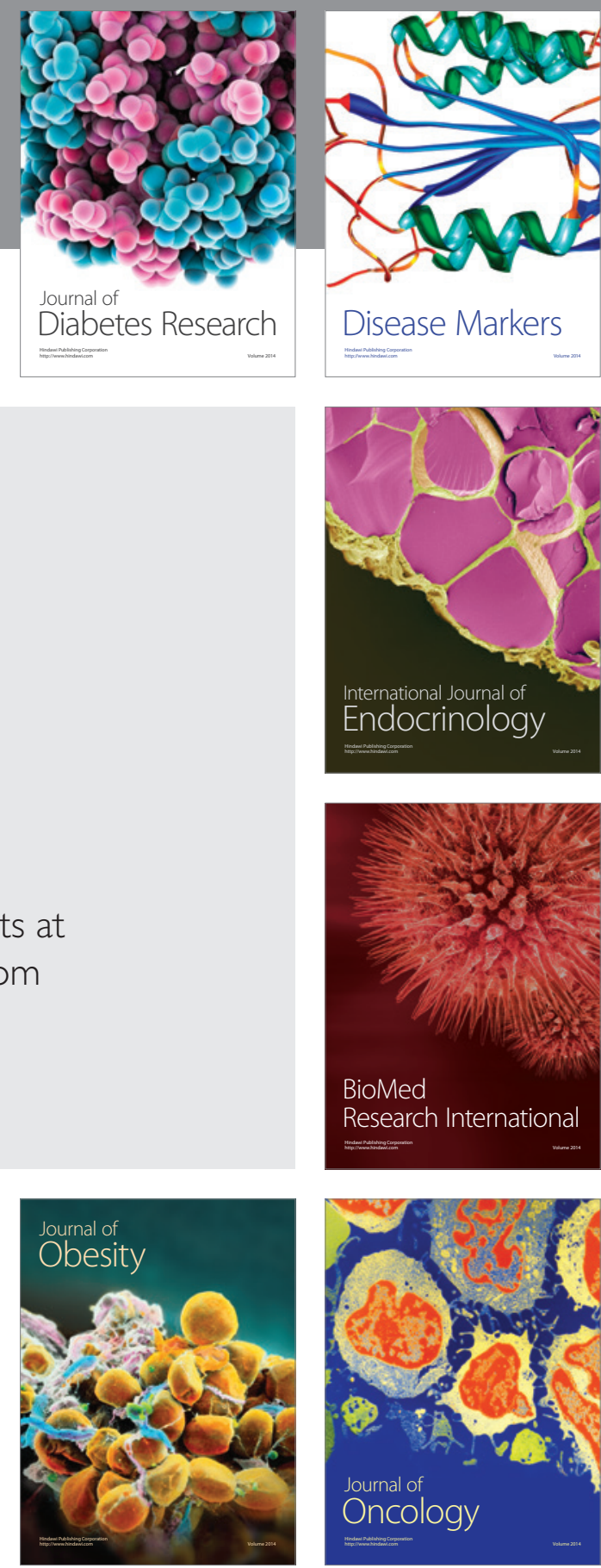

Disease Markers
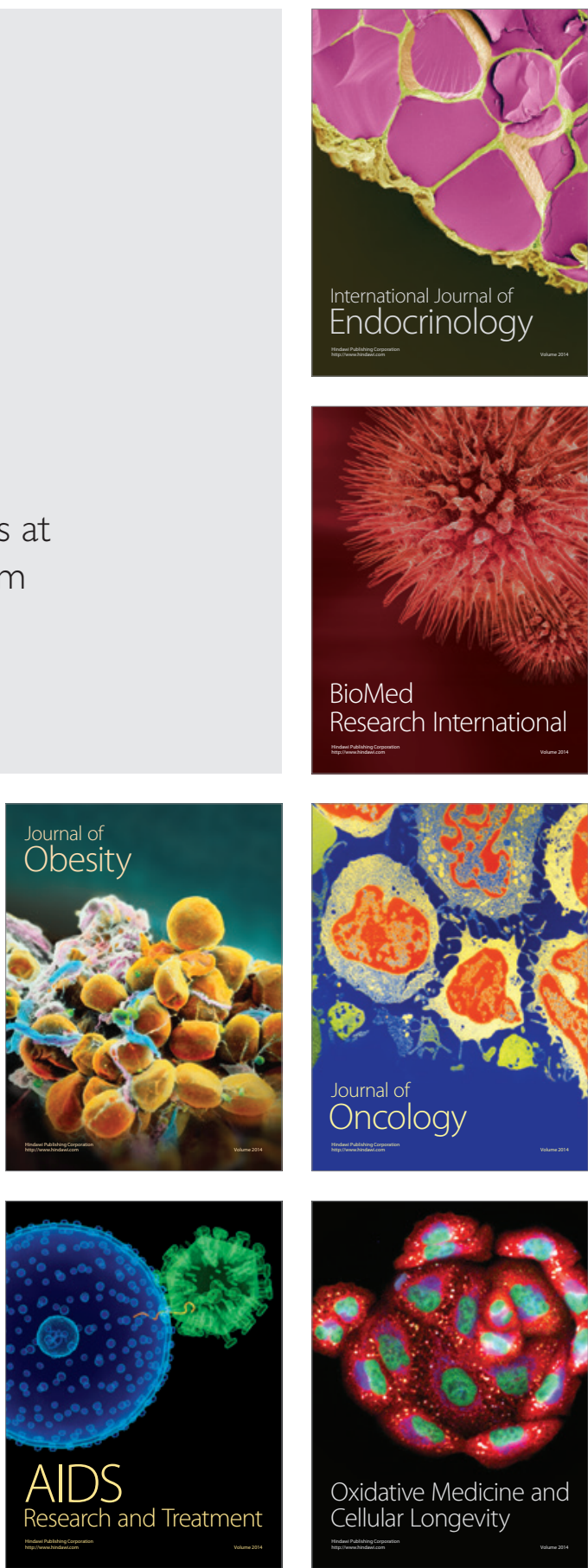